\title{
Prenatal and postnatal maternal contributions in the infection model of schizophrenia
}

\section{Conference Paper}

Author(s):

Meyer, Urs; Schwendener, Severin; Feldon, Joram; Yee, Benjamin K.

Publication date:

2006-08

Permanent link:

https://doi.org/10.3929/ethz-b-000000865

Rights / license:

In Copyright - Non-Commercial Use Permitted

Originally published in:

Experimental Brain Research 173(2), https://doi.org/10.1007/s00221-006-0419-5 


\section{Prenatal and postnatal maternal contributions in the infection model of schizophrenia}

Received: 2 February 2006 / Accepted: 21 February 2006 / Published online: 22 March 2006

(C) Springer-Verlag 2006

\begin{abstract}
Epidemiological studies have indicated that the risk of schizophrenia is enhanced by prenatal maternal infection with viral or bacterial pathogens. Recent experimentation in rodents has yielded additional support for a causal relationship between prenatal immune challenge and the emergence of psychosis-related abnormalities in brain and behaviour in later life. However, little is known about the putative roles of maternal postnatal factors in triggering and modulating the emergence of psychopathology following prenatal immunological stimulation. Here, we aimed to dissect the relative contributions of prenatal inflammatory events and postnatal maternal factors in precipitating juvenile and adult psychopathology in the resulting offspring with a crossfostering design. Pregnant mice were exposed to the viral mimic, polyriboinosinic-polyribocytidilic acid (PolyI:C; at $5 \mathrm{mg} / \mathrm{kg}$, intravenously), or vehicle treatment on gestation day 9, and offspring born to PolyI:C- and vehicletreated dams were then simultaneously cross-fostered to surrogate rearing mothers, which had either experienced inflammatory or vehicle treatment during pregnancy. Prenatal PolyI:C administration did not affect the expression of latent inhibition (LI) at a juvenile stage of development, but led to the post-pubertal emergence of LI disruption in both aversive classical and instrumental conditioning regardless of the postnatal rearing condition. In addition, deficits in conditioning as such led to a pre- and post-pubertal loss of LI in prenatal control animals that were adopted by PolyI:C-treated surrogate mothers. Our findings thus indicate that the adoption of prenatally immune-challenged neonates by control surrogate mothers does not possess any protective effects against the subsequent emergence of psychopathology in
\end{abstract}

U. Meyer · S. Schwendener · J. Feldon · B. K. Yee $(\bowtie)$

Laboratory of Behavioural Neurobiology,

Swiss Federal Institute of Technology Zurich,

Schorenstrasse 16, 8603 Schwerzenbach, Switzerland

E-mail: byee@ethz.ch

Tel.: +41-1-6557417

Fax: +41-1-6557203 adulthood. At the same time, however, the present study highlights for the first time that the adoption of prenatal control animals by immune-challenged rearing mothers is sufficient to precipitate learning disabilities in the juvenile and adult offspring.

Keywords Adoption - Animal model - Cytokines . Infection $\cdot$ Latent inhibition - Learning $\cdot$ PolyI:C · Schizophrenia

\section{Introduction}

Epidemiological evidence for a link between maternal bacterial and viral infections during pregnancy and increased risk in the offspring for schizophrenia and related disorders (Mednick et al. 1988; O'Callaghan et al. 1994; Hultman et al. 1999; Brown et al. 2000, 2004a) has led to recent attempts to model the mechanisms involved in animals. Support for a causal relationship between in utero immunological challenge and enhanced prevalence of psychosis-related behavioural, cognitive and pharmacological abnormalities in later life has been established in rats and mice using bacterial endotoxin (Borrell et al. 2002; Fortier et al. 2004; Golan et al. 2005), human influenza virus (Shi et al. 2003) or a synthetic viral mimic (Zuckerman et al. 2003a; Zuckerman and Weiner 2003, 2005; Meyer et al. 2005; 2006; Ozawa et al. 2006). Prenatal immunological stimulation has also been shown to result in long-term structural alterations in the hippocampus and cortical mantle in neonatal and adult offspring (Fatemi et al. 1999, 2002; Golan et al. 2005) and in altered expressions of genes implicated in schizophrenia (Fatemi et al. 2005; Harrison and Weinberger 2005). The functional consequences of prenatal immune challenge typically remain behaviourally latent until adulthood when the impact of the prenatal immunological manipulation on behaviour and cognition eventually unfolds (Zuckerman et al. 2003a; Zuckerman and Weiner 2003; Ozawa et al. 2006). This maturational delay 
between the immunological manipulation in utero and the onset of psychopathology in adulthood agrees well with the developmental aetiology and disease process of schizophrenia and related disorders (Weinberger 1987; Rapoport et al. 2005).

The precise mechanisms underlying the epidemiological link between maternal infection during pregnancy and increased risk for schizophrenia in the offspring remain largely unknown. One hypothesis asserts that the maternal immune response to the infectious process may be the critical link in this association (Buka et al. 2001; Pearce 2001; Patterson 2002; Brown et al. 2004b). In particular, it has been suggested that the elevation of pro-inflammatory cytokines in the maternal host and thereafter in the foetal environment may be one of the key events in triggering mal-neurodevelopment in the developing foetus (Gilmore and Jarskog 1997; Urakubo et al. 2001; Gilmore et al. 2004, 2005; Ashdown et al. 2006). Hence, inflammation-mediated disruption of foetal brain development may predispose the early organism to the emergence of psychopathological traits in later life, suggesting furthermore that neurodevelopmental perturbations implicated in the ethiopathogenesis of schizophrenia already start in utero (Jakob and Beckman 1986; Bracha et al. 1991, 1992; Murray et al. 1991; Gilmore et al. 1996).

However, the rodent and primate brain undergoes significant development and maturation in early postnatal life, which is characterized by an intricate motherinfant relationship (Fleming et al. 1999). It is therefore not surprising that early life adversity in the form of child neglect and/or abuse is a critical factor in the development of affective psychopathology in humans (Parker et al. 1995; Lehmann and Feldon 2000; Kendler et al. 2002, 2006; Cirulli et al. 2003; Pryce and Feldon 2003; Pryce et al. 2005). Moreover, human adoption studies have demonstrated that adoptees with a high genetic risk for schizophrenia are significantly more sensitive to adverse rearing patterns in adoptive families than are adoptees at low risk (Wahlberg et al. 1997; Tienari et al. 2004; Mäki et al. 2005), and therefore are more prone to the emergence of psychosis in later life. This is in full agreement with the hypothesis that the aetiology of schizophrenia involves the combined effects of environmental and genetic factors (Franzek and Beckmann 1996; Cardno et al. 1999; Tsuang 2000; Petronis 2004). Experimentation in animals has further confirmed that interference to normal postnatal mother-infant interactions can induce psychosis-related behavioural and pharmacological abnormalities in the offspring (Weiss and Feldon 2001; Weiss et al. 2001; Ellenbroek and Cools 2002; Brake et al. 2004).

Maternal stress during pregnancy represents a psychophysiological event that can alter postpartum maternal behaviour and thus expose the developing offspring to adverse postnatal rearing environment (Brayden et al. 1992; Maughan and McCarthy 1997; Meek et al. 2001; Patin et al. 2002). However, although immunological stimulation is strongly associated with activation of the stress response axes (Goebel et al. 2002; Haddad et al. 2002; Webster and Sternberg 2004; Silverman et al. 2005), it is virtually unknown whether gestational immune challenge is associated with alterations in postpartum maternal behaviour. Hence, the role of postnatal maternal factors in the precipitation of psychosis-related abnormalities following prenatal immune challenge still remains uncharted.

We therefore sought to dissect the relative contributions of prenatal inflammatory events and postnatal maternal factors in triggering and precipitating psychopathology in the offspring. Here, pregnant mice were exposed to the inflammatory agent polyriboinosinicpolyribocytidilic acid (PolyI:C) or vehicle treatment on gestation day (GD) 9, and the offspring derived were then cross-fostered to surrogate rearing mothers, which previously had either experienced inflammatory or vehicle treatment during pregnancy. The effectiveness of GD 9 PolyI:C treatment to induce psychosis-related behavioural, cognitive and neurochemical abnormalities in the offspring has been firmly established before (Shi et al. 2003; Meyer et al. 2005, 2006). In the present study, we aimed to elucidate the relative effects of the prenatal and postnatal factors specifically on the development and expression of latent inhibition (LI). LI is a selective learning paradigm, in which prior repeated pre-exposures to the to-be-conditioned stimulus retards subsequent development of the conditioned response (CR) following explicit parings between the same conditioned stimulus (CS) and an unconditioned stimulus (US). Deficiency in LI has been related to the attentional deficits commonly observed in schizophrenic patients (Feldon and Weiner 1992; Gray et al. 1991; Gray 1998; Weiner 2003), which may be central to the patients' difficulties in forming, maintaining and/or retrieving selective associations between events (Hemsley 1976; Frith 1979; Nuechterlein and Dawson 1984; Perry and Braff 1994).

Here, three different conditioning procedures were used to asses juvenile and adult LI, namely conditioned freezing, conditioned active avoidance and conditioned taste aversion. This allowed us to study the relative effects of the prenatal and postnatal manipulations on the development of adult LI without any potential confounds resulting from repeated testing with the same behavioural paradigm from pre-adolescence to adulthood, and it further served to verify the generality of our findings across different conditioning procedures in adulthood.

\section{Materials and methods}

\section{Animals}

Female and male C57BL6/J breeders were obtained from our in-house specific pathogen-free (SPF) colony at the age of 10-14 weeks. Littermates of the same sex were kept in groups of 3-5 mice. Breeding began after 2 weeks 
of acclimatization to the new animal holding room. The breeding procedure and the verification of pregnancy have been fully described before (Meyer et al. 2005). All procedures described in the present study had been previously approved by the Swiss Cantonal Veterinary Office, and are in agreement with the Principles of Laboratory Animal Care (NIH publication No. 86-23, revised 1985).

\section{Prenatal treatment}

Pregnant dams on GD 9 received either a single injection of PolyI:C or vehicle solution (saline) via the intravenous route at the tail vein under mild physical constraint. PolyI:C (potassium salt) was obtained from Sigma Aldrich (Switzerland) and dissolved in saline to obtain the desired dosage $(5 \mathrm{mg} / \mathrm{kg}$, calculated based on the pure form PolyI:C). The volume of injection was $5 \mathrm{ml} / \mathrm{kg}$. All animals were immediately returned to the home cage after the injection procedure.

\section{Postnatal cross-fostering}

On the day of birth [postnatal day (PND) 0], the offspring born to PolyI:C- and vehicle-treated dams were culled to litters of 6-8 animals each (with 3-4 animals per sex) and cross-fostered to surrogate rearing mothers. Male and female pups were removed from the original mother and gently placed in a cage containing sawdust bedding for a maximal total of $10 \mathrm{~min}$. Half of a given litter was then placed with a PolyI:C-treated surrogate rearing mother and the other half with a vehicle-treated rearing mother. Each surrogate mother thus simultaneously fostered pups originating from both prenatal treatment conditions, but not its own offspring. PolyI:C and vehicle offsprings were marked on the left and right hind paw, respectively. A total of 24 litters (12 PolyI:C and 12 vehicle) were cross-fostered to 24 rearing mothers, half of which had been subjected to PolyI:C exposure during pregnancy and the other half to vehicle treatment only.

The cross-fostering resulted in four experimental treatment groups: (1) offspring subjected to prenatal vehicle exposure and raised by a vehicle-treated surrogate mother (SAL-SAL), (2) offspring subjected to prenatal vehicle exposure and raised by a PolyI:C-treated surrogate mother (SAL-POL), (3) offspring subjected to prenatal PolyI:C exposure and raised by a vehicle-treated surrogate mother (POL-SAL), and (4) offspring subjected to prenatal PolyI:C exposure and raised by a PolyI:C-treated surrogate mother (POL-POL).

\section{Behavioural testing}

The offspring were weaned and sexed at PND 24. The pups were weighed and littermates of the same sex were caged separately, thereby separating the animals according to the four treatment conditions. All animals were maintained under ad libitum food (Kliba, 3430,
Klibamühlen, Kaiseraugst, Switzerland) and water diet, and kept in a temperature and humidity-controlled $\left(21 \pm 1^{\circ} \mathrm{C}, 55 \pm 5 \%\right)$ animal vivarium under a $12: 12 \mathrm{~h}$ reversed light-dark cycle (lights off at $0700 \mathrm{~h}$ ).

Experiment 1 assessed LI in pre-adolescence, i.e. when the offspring reached 35-45 days of age, and only included male subjects. Each of the four treatment groups consisted of subjects derived from multiple independent litters formed by the cross-fostering procedure. Animals belonging to the same litter were, as far as possible, allocated evenly across levels of the between-subject factors of pre-exposure in each experiment, namely the non-pre-exposed (NPE) and pre-exposed (PE) conditions, in order to minimize potential confounds resulting from litter effects (Zorrilla 1997).

Experiments 2 and 3 tested LI in adulthood, i.e. when the offspring reached PND 95-135, and were conducted in both experimentally naïve animals and animals that had been previously tested in pre-adolescence (Experiment 1). Again, only male subjects were included. They were evenly distributed across levels of the between-subject factors of pre-exposure (NPE and PE), with the previous pre-exposure experience in Experiment 1 counterbalanced across the two pre-exposure conditions. The number of subjects employed in each of the behavioural tests is listed in Table 1.

Experiment 1: assessment of LI using a conditioned freezing paradigm in pre-adolescence

The apparatus comprised two sets of four test chambers. One set consisted of four metal operant boxes $(30 \times 25 \times 29 \mathrm{~cm}$; Model E10-10, Coulbourn Instruments, Allentown, PA, USA), each installed in a ventilated and sound-insulated Coulbourn Instruments chest. The animal was confined to a rectangular enclosure $(17.5 \times 13 \mathrm{~cm})$ in the middle of the operant box. The other set of four chambers comprised four semi-circular (19 cm in diameter) Plexiglas enclosures, each installed in a ventilated, sound-insulated, wooden cabinet. The construction of the test chambers as well as the image analysis software used to evaluate freezing behaviour has been fully described previously (Meyer et al. 2005).

The test procedures consisted of four phases: Preexposure, conditioning, context test and CS test. In the pre-exposure phase, the animals were placed in the appropriate test chamber: CS-pre-exposed (CS-PE) subjects received 40 presentations of a 30 -s tone stimulus at a variable inter-stimulus interval of $40 \pm 30 \mathrm{~s}$; NPE subjects were confined to the chamber for an equivalent period of time without any stimulus presentation. Conditioning commenced immediately at the end of the preexposure phase without removing the animals from the chambers. Conditioning comprised three discrete trials of CS-US pairings. Each trial began with the 30-s tone stimulus (identical to the one used during pre-exposure) followed immediately by the delivery of a 1-s foot-shock set at $0.3 \mathrm{~mA}$. Each trial was preceded and followed by a 180 -s interval. 
Table 1 Sample size of each treatment group and experimental conditions

\begin{tabular}{|c|c|c|c|c|c|}
\hline \multirow[t]{2}{*}{ Experiments } & \multicolumn{4}{|c|}{ Experimental groups (prenatal treatment-postnatal rearing) } & \multirow{2}{*}{$\begin{array}{l}\text { Postnatal } \\
\text { days (PNDs) }\end{array}$} \\
\hline & SAL-SAL & SAL-POL & POL-SAL & POL-POL & \\
\hline \multicolumn{6}{|l|}{ Body weight } \\
\hline Pre-adolescence & $6 \widehat{0} 6$ 우 & $6 \widehat{0} 4$ 우 & $6 \hat{0} 6$ 우 & $6 \widehat{3} 8$ 웅 & 35 \\
\hline Adulthood & $4 \widehat{\jmath} 6$ 우 & $5 \hat{\circ} 5$ 우 & $6 \hat{3} 8+$ & $9 \hat{\jmath} 8$ + & 95 \\
\hline \multicolumn{6}{|c|}{$\begin{array}{l}\text { Experiment 1: } \\
\text { pre-adolescent } \\
\text { LI in conditioned } \\
\text { freezing }\end{array}$} \\
\hline NPE & $8 \hat{0}$ & $7 \hat{\jmath}$ & $6 \hat{0}$ & $6 \hat{\jmath}$ & $35-45$ \\
\hline $\mathrm{PE}$ & $7 \hat{\jmath}$ & $7 \hat{\jmath}$ & $8 \hat{0}$ & $6 \hat{0}$ & \\
\hline \multicolumn{6}{|c|}{$\begin{array}{l}\text { Experiment 2: } \\
\text { adult LI in } \\
\text { conditioned } \\
\text { active avoidance }\end{array}$} \\
\hline NPE & $6 \hat{0}$ & $7 \hat{\jmath}$ & $5 \hat{\jmath}$ & $5 \hat{\jmath}$ & $95-110$ \\
\hline PE & $6 \hat{\jmath}$ & $6 \hat{\jmath}$ & $6 \hat{\circ}$ & $6 \hat{\jmath}$ & \\
\hline \multicolumn{6}{|l|}{$\begin{array}{l}\text { Experiment 3: } \\
\text { adult LI in } \\
\text { conditioned } \\
\text { taste aversion }\end{array}$} \\
\hline NPE & $4 \hat{\jmath}$ & $5 \hat{\circ}$ & $5 \hat{\circ}$ & $4 \hat{\jmath}$ & $120-135$ \\
\hline $\mathrm{PE}$ & $4 \hat{\jmath}$ & $4 \hat{\jmath}$ & $4 \widehat{\jmath}$ & $5 \hat{\jmath}$ & \\
\hline
\end{tabular}

Offspring born to saline (SAL)- and PolyI:C (POL)-treated dams were cross-fostered to surrogate rearing mothers, which had been exposed to either saline or PolyI:C during pregnancy; this yielded four experimental groups according to a two (prenatal treatment) $\times$ two (postnatal rearing condition) design. The body weight of experimentally naïve male and female subjects was measured in both pre-adolescence (i.e. at postnatal day (PND) 35) and in adulthood (PND 95). Latent inhibition (LI) was first assessed in male animals when they reached PND 35 of age using a conditioned freezing paradigm (Experiment 1). Next, adult LI was measured in three to four subjects (per pre-exposure condition) that had been previously tested in pre-adolescence, in addition to experimentally naïve adult subjects, using a two-way active avoidance paradigm at PND 95-110 (Experiment 2). Adult LI was also assessed in conditioned taste aversion (Experiment 3) at PND 120-135 using animals with a juvenile test-history (two to three per pre-exposure condition) and experimentally naïve adult subjects. As far as possible, the pre-exposure experience (i.e. NPE and PE) of the juvenile test history was counterbalanced across the pre-exposure conditions in adult testing

The context test took place $24 \mathrm{~h}$ later when the subjects were returned to the same chambers for a period of $480 \mathrm{~s}$ in the absence of any discrete stimulus.

The test of conditioned responding to the tone CS was conducted another $24 \mathrm{~h}$ later, when the animals were placed in the same test chambers again. Following an initial period of $180 \mathrm{~s}$ acclimatization, the tone CS was delivered and remained on for $480 \mathrm{~s}$, and the amount of time conditioned freezing occurred in the presence of the tone stimulus was recorded as described before (Meyer et al. 2005, 2006). The test phase was concluded with a final 180 s CS-free period.

The data on freezing behaviour collected in the three phases (conditioning, context-test, CS-test) were analysed separately.

Experiment 2: assessment of LI using a two-way active avoidance paradigm in adulthood

The apparatus consisted of four identical two-way shuttle boxes (model H10-11M-SC; Coulbourn Instruments) as described before (Meyer et al. 2006). The internal dimensions of each shuttle box, as measured from the raised grid floor, were $35.5 \times 18 \times 32.5 \mathrm{~cm}$. The box was separated by an aluminium wall into two identical compartments, which were interconnected by an opening $(6.5 \times 8 \mathrm{~cm})$ in the parti- tion wall, thus allowing the animal to freely traverse from one compartment to the other. The grid floor was made of stainless steel rods, $4 \mathrm{~mm}$ in diameter and spaced $7 \mathrm{~mm}$ apart (centre to centre), and was connected to a constant current shock generator (model H10-1 M-XX-SF; Coulbourn Instruments). Through the grid floor, an electric shock $(0.3 \mathrm{~mA})$ could be delivered. The CS was an $80-\mathrm{dB}_{\mathrm{A}}$ white noise delivered by a speaker placed on the floor of the cubicle and behind outside the shuttle box. Shuttle response was detected by a series of photocells (H20-95X, Coulbourn Instruments) mounted on the side of both shuttle compartments. The boxes were illuminated throughout the experimental session by two diffuse light sources $(1.1 \mathrm{~W})$, each mounted $19 \mathrm{~cm}$ above the grid floor on the sidewall on each of the two compartments.

The test procedures consisted of two phases: preexposure and conditioning, conducted $24 \mathrm{~h}$ apart. Animals from each of the four treatment groups were allocated to one of two conditions: CS-pre-exposure (PE) and non-pre-exposure (NPE).

In the pre-exposure phase, the PE subjects were placed in the appropriate test chambers and presented with 100 pre-exposures to a 5-s noise CS according to a random inter-stimulus interval schedule of $40 \pm 15 \mathrm{~s}$. The NPE subjects were confined to the chamber for an equivalent period of time without any stimulus presentation. 
The total number of shuttle responses performed during the pre-exposure session was recorded.

On the conditioning day, the subjects were returned to the same shuttle boxes and received a total of 100 avoidance trials presented with an ITI of $40 \pm 15 \mathrm{~s}$. Each avoidance trial began with the onset of the white noise CS. If an animal made a shuttle into the adjacent compartment within $5 \mathrm{~s}$ of the CS onset, the CS would be terminated without any delivery of the shock-US and an avoidance response was scored. Avoidance failure led immediately to an electric foot-shock presented coincident with the CS. This could last for a maximum of $2 \mathrm{~s}$, but would be terminated by a shuttle response during this period, which would then be counted as an escape response. To index conditioned avoidance learning, the mean avoidance response per ten-trial block was submitted to statistical analysis.

Experiment 3: assessment of LI using a conditioned taste aversion paradigm in adulthood

The apparatus consisted of Macrolon type III cages with modified grid tops, which allowed the efficient placement or removal of the drinking tubes (two per cage). The apparatus has been fully described elsewhere (Meyer et al. 2004).

The animals were kept singly in the modified cages throughout the experiment. One day after the animals were switched to single caging, they were gradually introduced to a water deprivation regime over a 5-day period to achieve $23 \mathrm{~h}$ water deprivation on the fifth day. On all subsequent days, the animals were allowed daily access to fluid in two 30 -min periods, separated by a 5-h interval. During the first drinking period, the animals had free access to two tubes, and the second period always consisted of water only, which was presented in regular water bottles. The experimental procedures consisted of four stages: baseline, pre-exposure, conditioning and test.

\section{Baseline}

From days 1 to 4 , the animals were allowed access to water in both drinking periods on each day. This served to stabilize the volume of daily water intake. The allocation of the subjects to the two pre-exposure conditions was counterbalanced in each treatment group according to the animals' baseline performance.

\section{Pre-exposure}

On day 5, animals allocated to the NPE groups had access to water as described above. Animals in the PE groups were given access to $10 \%$ sucrose solution in both drinking tubes during the first drinking period. The amount of liquid consumption was recorded (sucrose solution for PE subjects, and water for NPE subjects).

\section{Conditioning}

On day 6, all animals were given access to $10 \%$ sucrose solution presented in two drinking tubes for a total of
$30 \mathrm{~min}$, followed by an intraperitoneal (i.p.) administration of lithium chloride $(\mathrm{LiCl})$ solution 5 min later. $\mathrm{LiCl}$ was dissolved in $0.9 \% \mathrm{NaCl}$ to achieve a concentration of $0.25 \mathrm{M}$ on the day of administration. It was injected in a volume of $2 \% \mathrm{v} / \mathrm{w}$ body weight. The amount of sucrose intake on the conditioning session was recorded.

\section{Test}

On day 7, conditioned aversion to the sucrose taste was measured in a two-choice test with one drinking tube filled with $10 \%$ sucrose solution, and the other with water, and indexed by sucrose consumption as a proportion (in percent) of total liquid consumed during the first drinking period when the animals were confronted with a choice between sucrose and water. The data collected on the four phases were analysed separately.

\section{Statistical analysis}

All data were analysed using parametric analysis of variance (ANOVA) followed by separate ANOVAs restricted to the prenatal and/or postnatal treatment conditions whenever a main effect or interaction involving the factor of treatment attained statistical significance. Statistical significance was set at $P<0.05$. All statistical analyses were carried out using the statistical software StatView (version 5.0) implemented on a PC running the Windows XP operating system. Preliminary analyses indicated that the test history never interacted with any of the between-subject factors of treatment and of pre-exposure in Experiments 2 and 3, so that experimentally naïve subjects and animals having been tested in pre-adolescence (Experiment 1) were combined in the final analysis and in the presentation of the behavioural results obtained in Experiments 2 and 3.

\section{Results}

Body weights

Body weights of experimentally naïve female and male subjects measured on PND 35 and PND 95 were analysed separately using $2 \times 2 \times 2$ (sex $\times$ prenatal treatment $\times$ postnatal rearing) randomized block ANOVA.

The analysis conducted on the body weights at PND 35 revealed no significant main effects or interactions involving any of the three between-subject factors. The overall mean body weight ( \pm SEM) of subjects at PND 35 was $19.02 \pm 0.35 \mathrm{~g}$.

At PND 95, however, the body weight of female subjects was generally lower compared to male animals, as indicated by the presence of a significant main effect of sex $[F(1,64)=61.13, P<0.001]$. In addition, the adoption of neonates by PolyI:C-exposed surrogate rearing mothers resulted in a decrease in their body weight, and this effect was independent of sex and prenatal treatment history. 
This impression was supported by the presence of a significant main effect of postnatal rearing $[F(1,64)=4.34$, $P<0.05]$. The mean body weight $( \pm$ SEM) of offspring raised by vehicle-treated surrogate mothers was $27.68 \pm 0.58 \mathrm{~g}$, and that of animals adopted by PolyI:Cexposed rearing mothers was $23.72 \pm 0.63 \mathrm{~g}$. No other main effects or interactions attained statistical significance.

Experiment 1: assessment of LI using a conditioned freezing paradigm in pre-adolescence

\section{Conditioning}

The development of the conditioned freezing response was assessed by comparing the levels of percent time freezing at the three successive presentations of the tone CS. The percentage of time freezing was submitted to a $2 \times 2 \times 2 \times 3$ (prenatal treatment $\times$ postnatal rearing $\times$ preexposure $\times$ trials) split-plot ANOVA.

The amount of freezing increased as a function of trials in all treatment groups as evident by the overall main effect of trials $[F(2,92)=125.70, P<0.001]$. The increase of percent time freezing across successive trials was retarded in PE animals compared to NPE subjects, leading to a significant main effect of pre-exposure $[F(1,46)=38.15$, $P<0.001]$ and its interaction with trials $[F(2,92)=17.96$, $P<0.001]$. However, the efficacy of repeated tone-stimulus pre-exposures to impede the generation of conditioned freezing to the tone (i.e. the LI effect) was enhanced in animals exposed to prenatal PolyI:C treatment regardless of the neonatal rearing condition, leading to the emergence of a significant prenatal treatment $\times$ pre-exposure $\times$ trials interaction term $[F(2,92)=4.27, P<0.05]$. Separate ANOVAs restricted to each of the four experimental conditions were then conducted at each of the three conditioning trials. These analyses showed that prior stimulus pre-exposures was effective in reducing the conditioned freezing response to the tone stimulus in the second trial in all experimental groups, as evident by the presence of a significant main effect of pre-exposure in each of the four groups [SAL-SAL: $F(1,13)=12.46, P<0.01$; SAL-POL: $F(1,12)=25.75, \quad P<0.001 ; \quad$ POL-SAL: $F(1,12)=17.60$, $P<0.001$; POL-POL: $F(1,9)=16.25, P<0.001]$. However, this CS-pre-exposure effect disappeared by the third conditioning trial in animals exposed to prenatal vehicle treatment [SAL-SAL and SAL-POL animals: $F \mathrm{~s}<1.0, \mathrm{~ns}$ ], but persisted into the final trial in prenatal PolyI:C-offspring regardless of the postnatal rearing condition [POL-SAL: $F(1,12)=4.79, \quad P<0.05 ; \quad$ POL-POL: $\quad F(1,9)=24.24$, $P<0.001$ ] (Fig. 1).

\section{Context-freezing}

The expression of conditioned freezing towards the context in which conditioning took place was assessed when the animals were returned to the conditioning chamber $24 \mathrm{~h}$ following conditioning. Data were expressed as percent time freezing per 1-min bin and analysed using a $2 \times 2 \times 2 \times 8$ (prenatal treatment $\times$ postnatal rearing $\times$ preexposure $\times$ trials) split-plot ANOVA.

There was a general increase in the level of freezing as a function of time, leading to a significant main effect of bins
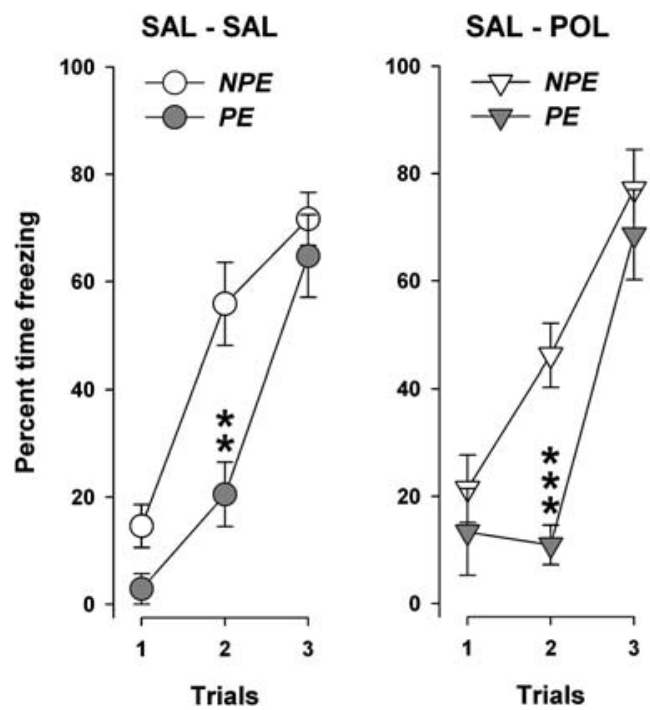

Fig. 1 The effects of the prenatal and postnatal manipulations on the acquisition of the freezing response on the conditioning day in pre-adolescence. The development of the conditioned freezing response was assessed by comparing the levels of percent time freezing at successive presentations of the tone conditioned stimulus $(C S)$, which was immediately followed by a 1-s foot shock. Repeated preexposures to the tone stimulus was effective in retarding the expression of freezing to the tone in all experimental groups, and this latent inhibition $(L I)$ effect was particularly evident during the second
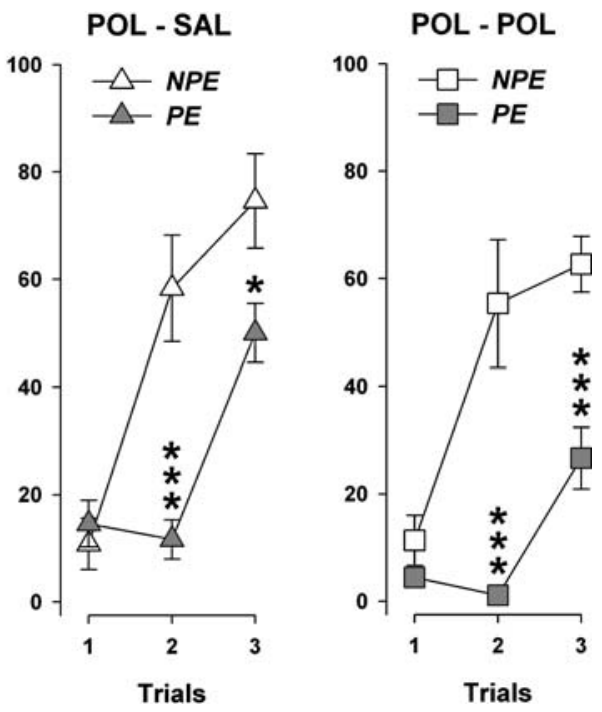

conditioning trial. However, in contrast to juvenile animals that were subjected to prenatal vehicle treatment (i.e. $S A L-S A L$ and $S A L-P O L$ offspring), the LI effect persisted into the third conditioning trial in prenatally PolyI:C-exposed subjects regardless of the postnatal rearing condition (i.e. in $P O L-S A L$ and $P O L-P O L$ offspring). All values refer to mean \pm SEM. Symbols $(* *)$ and $(* * *)$ refer to a statistical significance of $P<0.01$ and $P<0.001$, respectively, based on separate ANOVAs restricted to each conditioning trial and experimental treatment group 
$[F(7,322)=12.60, P<0.001]$. However, the expression of freezing towards the context was generally low, and no other main effects or interactions involving the factors of treatment or pre-exposure attained statistical significance. The overall mean \pm SEM of context-freezing per pre-exposure condition was $10.83 \pm 1.65$ (NPE) and 10.90 \pm 2.19 (PE).

\section{Tone-freezing}

The level of freezing during the 3-min pre-tone period was generally low, and no significant group differences were detected in the analysis of percent time freezing over this period.

Conditioned freezing towards the discrete tone CS was assessed $48 \mathrm{~h}$ following conditioning. For the purpose of analysis, the percentage of time freezing during the first 3-min period of the tone presentation was expressed as a function of 1-min bins and subjected to a $2 \times 2 \times 2 \times 3$ (prenatal treatment $\times$ postnatal rearing $\times$ preexposure $\times 1$-min bins) split-plot ANOVA.

Non-pre-exposed subjects generally showed a higher level of freezing towards the tone than PE animals, leading to a significant main effect of pre-exposure $[F(1,46)=12.56, P<0.001]$. However, the presence of a significant prenatal treatment $\times$ postnatal rearing $\times$ preexposure $[F(2,92)=4.49, \quad P<0.05]$ interaction term indicated that the expression of LI in the tone test was differentially affected by both the prenatal and postnatal treatment. Subsequent analyses restricted to each of the four treatment conditions revealed a significant pre-exposure effect in animals that were subjected to prenatal vehicle treatment and raised by a vehicle-treated surrogate mother (SAL-SAL offspring) $[F(1,13)=6.12, P<0.05]$ and in animals that were exposed to prenatal PolyI:C treatment, independent of the postnatal rearing condition
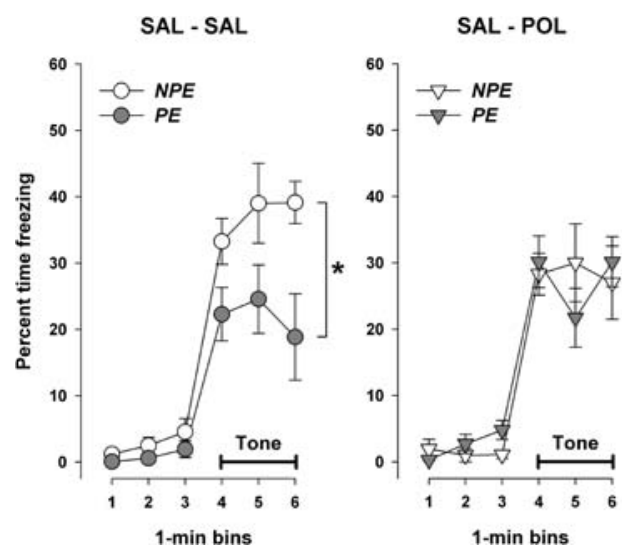

Fig. 2 The effects of the prenatal and postnatal manipulations on the expression of LI during the test of conditioned tone-freezing in pre-adolescence. Conditioned freezing was assessed over a period of $180 \mathrm{~s}$ in the presence of the tone CS. For every experimental group, the freezing response is plotted as a function of 1-min bins for the initial 3-min pre-tone period, in which no explicit stimulus was presented, and for the subsequent tone-presentation period. Following the onset of the tone-CS, a significant presence of LI was observed in juvenile offspring that were subjected to prenatal vehicle (saline)
[POL-SAL offspring: $[F(1,12)=13.12, P<0.01$; POLPOL offspring: $F(1,9)=12.75, P<0.01]$ (Fig. 2). In contrast, no equivalent pre-exposure effect was detected in animals that were subjected to prenatal vehicle treatment and adopted by PolyI:C-exposed rearing mothers due to the reduction in the freezing response displayed by NPE subjects $[F<0.01$, ns] (Fig. 2).

In order to further assess the effects of the prenatal and postnatal manipulations on the expression of the tone-freezing response per se, an additional $2 \times 2 \times 3$ (prenatal treatment $\times$ postnatal rearing $\times 1$-min bins) splitplot ANOVA restricted to NPE subjects was conducted. This analysis showed that the prenatal administration of PolyI:C enhanced the conditioned responding regardless of the postnatal rearing condition (Fig. 3), as supported by the significant main effect of prenatal treatment $[F(1,23)=11.27, P<0.01]$. In addition, the adoption of neonates by PolyI:C-treated surrogate mothers led to a marginal reduction in the expression of the tone-freezing response [main effect of postnatal rearing: $F(1,23)=3.04, P=0.095$ ] (Fig. 3). No interactions involving the two between-subject factors attained statistical significance.

Experiment 2: assessment of LI using a two-way active avoidance paradigm in adulthood

\section{Pre-exposure}

The total number of shuttle responses performed during the pre-exposure session was subjected to a $2 \times 2 \times 2$ (prenatal treatment $\times$ postnatal rearing $\times$ pre-exposure) randomized block ANOVA. This analysis yielded no significant main effects or interactions, and notably the spontaneous locomotor activity did not differ between

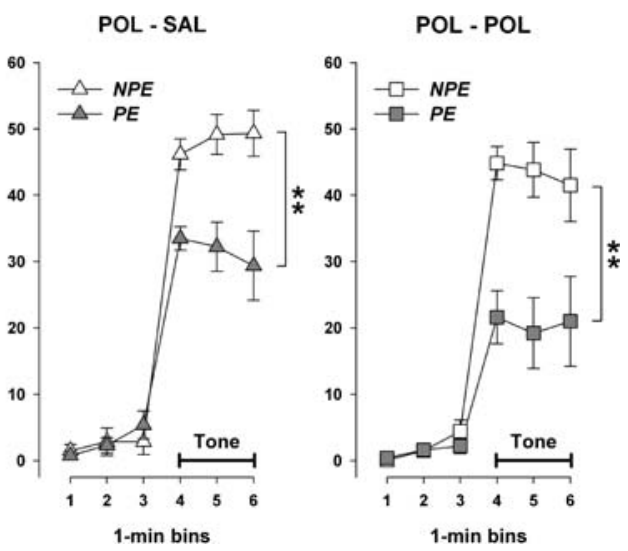

treatment and adopted by vehicle-treated surrogate mothers ( $S A L-$ $S A L$ ), as well as in animals that were exposed to prenatal PolyI:C treatment, independent of the postnatal rearing condition (i.e. in $P O L-S A L$ and $P O L-P O L$ animals). In contrast, a loss of the LI effect was detected in prenatally vehicle-treated offspring that were raised by PolyI:C-exposed surrogate mothers. All values refer to mean \pm SEM. Symbols $(*)$ and $(* *)$ refer to a statistical significance of $P<0.05$ and $P<0.01$, respectively, based on separate ANOVAs restricted to each experimental condition 

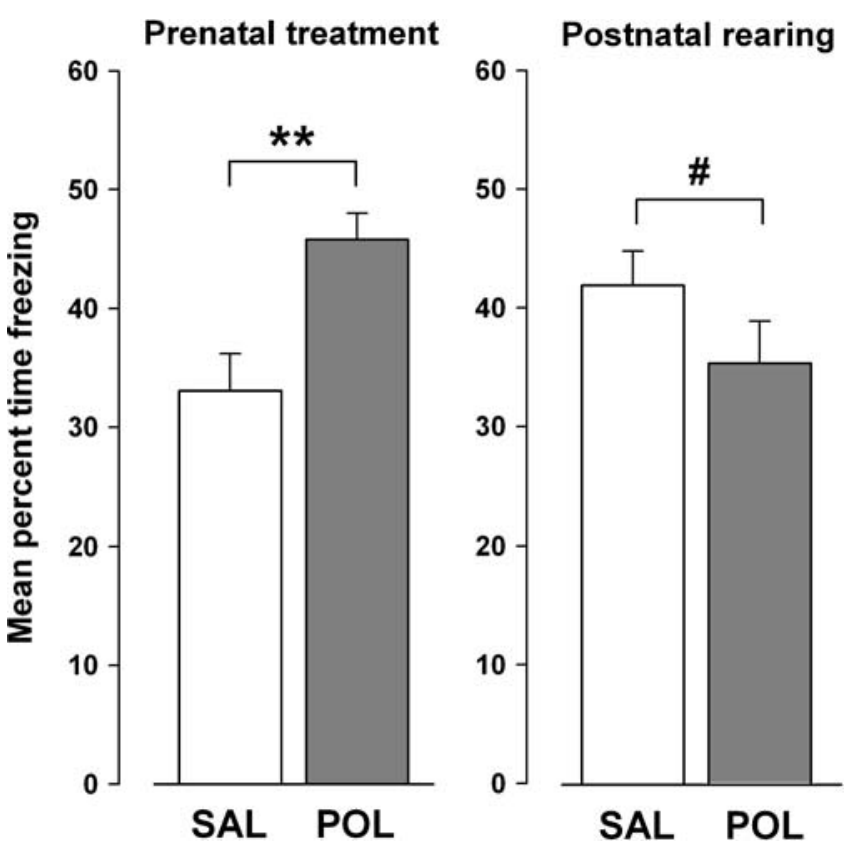

Fig. 3 The effects of the prenatal and postnatal manipulations on the expression of the conditioned freezing response in the non-preexposed $(N P E)$ condition during the tone-test day in pre-adolescence. The graph illustrates the overall mean percent time freezing displayed by NPE subjects during the 3-min period of the tone presentation. Animals subjected to prenatal PolyI:C (POL) exposure displayed an enhanced conditioned freezing response compared to offspring of dams treated with saline $(S A L)$ during mid-pregnancy, regardless of the postnatal rearing condition. In contrast, the adoption of neonates by PolyI:C-exposed surrogate mothers led to a marginal decrease in the tone-freezing response in juvenile animals. All values refer to mean \pm SEM. Symbols $(* *)$ and (\#) refer to a statistical significance of $P<0.01$ and $P<0.1$, respectively, associated with the main effects of prenatal treatment and postnatal rearing taken from the corresponding ANOVA restricted to NPE animals

treatment and pre-exposure conditions. The mean total number of spontaneous shuttles $( \pm$ SEM $)$ in the two preexposure conditions was: $\mathrm{NPE}=75 \pm 13$ and $\mathrm{PE}=66 \pm 9$.

\section{Conditioning}

Acquisition of conditioned avoidance responding was evident by an increase in the number of avoidance responses as a function of blocks, leading to a significant main effect of blocks $[F(9,342)=145.40, P<0.001]$ in a $2 \times 2 \times 2 \times 10$ (prenatal treatment $\times$ postnatal rearing $\times$ pre-exposure $\times$ ten-trial blocks) split-plot ANOVA of this measure. Both the prenatal treatment and the postnatal rearing condition affected the development of LI in conditioned avoidance learning. This was supported by the presence of the significant pre-exposure $\times$ prenatal treatment $[F(1,38)=5.11, P<0.05]$ and pre-exposure $\times$ postnatal rearing $\times$ blocks $[F(9,342)=2.94, \quad P<0.01]$ interaction terms. Subsequent analyses restricted to each of the four treatment conditions revealed a clear LI effect in animals that were exposed to prenatal vehicle treat- ment and raised by vehicle-treated surrogate mothers $[F(1,10)=40.83, P<0.001]$, i.e. with the PE subjects acquiring the avoidance response slower than the NPE subjects (Fig. 4). In contrast, this effect was equally absent in the other three treatment conditions, leading to the abolition of LI in these groups [all $\left.F_{\mathrm{S}}<1.0, \mathrm{~ns}\right]$.

An additional $2 \times 2 \times 10$ (prenatal treatment $\times$ postnatal rearing $\times$ ten-trial blocks) split-plot ANOVA restricted to the NPE condition was conducted in order to assess the effects of the prenatal and postnatal manipulations on conditioned avoidance learning per se. This analysis indicated that conditioned avoidance learning was impaired in offspring adopted by PolyI:C-treated surrogate mothers regardless of the offspring's prenatal treatment history (Fig. 5), as supported by the significant main effect of postnatal rearing $[F(1,19)=3.12, P<0.05]$ and its interaction with ten-trial blocks $[F(9,171)=4.56, P<0.001]$. In contrast, the prenatal history exerted no effects on avoidance learning in the NPE condition, as the main effect of prenatal treatment was far from significance $[F<1.0]$.

Experiment 3: assessment of LI using a conditioned taste aversion paradigm in adulthood

\section{Pre-exposure}

The amount of liquid consumption (sucrose solution for PE subjects, and water for NPE subjects) was subjected to a $2 \times 2 \times 2$ (prenatal treatment $\times$ postnatal rearing $\times$ preexposure) randomized block ANOVA. This analysis yielded no significant main effects or interactions, and notably the amount of liquid consumption was not affected by the pre-exposure or treatment conditions. The mean $( \pm$ SEM $)$ value of water consumption in the NPE subjects was $1.64 \pm 0.12 \mathrm{ml}$, and the mean $( \pm \mathrm{SEM})$ value of sucrose solution intake in the PE subjects was $1.48 \pm 0.05 \mathrm{ml}$.

\section{Conditioning}

The consumption of sucrose solution was affected by the sucrose pre-exposure history regardless of the prenatal and postnatal treatment conditions. PE subjects consumed more sucrose solution on the conditioning session compared to NPE subjects, leading to a significant main effect of pre-exposure in the ANOVA $[F(1,27)=7.13$, $P<0.01]$. The mean (SEM) value of sucrose solution consumption was: $\mathrm{NPE}=1.57 \pm 0.11 \mathrm{ml}, \mathrm{PE}=1.98 \pm 0.06 \mathrm{ml}$. No other main effects or interactions attained statistical significance.

\section{Testl}

Sucrose solution consumption as a proportion (in percent) of total liquid consumed was used to index conditioned taste aversion and the data were subjected to a three-way ANOVA as described before. Pre-exposure to the sucrose solution led to reduced conditioned taste aversion, i.e. PE subjects consumed a higher proportion 
SAL - SAL

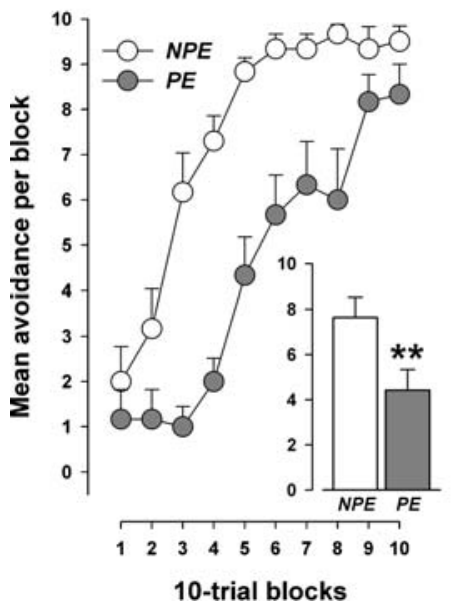

SAL - POL

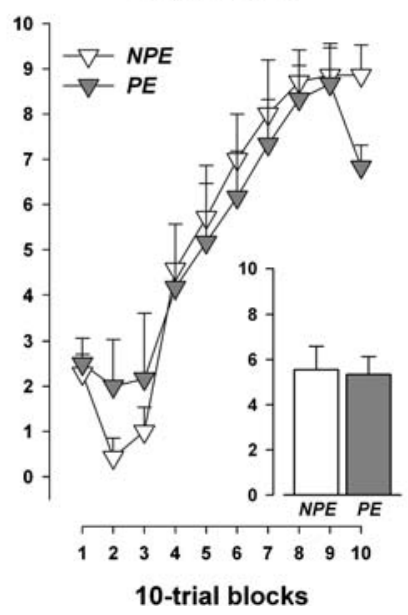

Fig. 4 The effects of the prenatal and postnatal manipulations on the development of LI in a two-way active avoidance paradigm in adulthood. Conditioned avoidance learning was indexed by the number of avoidance responses on the day of conditioning and expressed in successive ten-trial blocks. The embedded histograms illustrate the overall mean avoidance per block across the 100 conditioning trials. A clear LI effect was detected in adult offspring that were subjected to prenatal vehicle (saline) treatment and adopted by vehicle-treated

of sucrose solution than NPE subjects. However, this LI effect was present only in animals exposed to prenatal vehicle treatment but was absent in animals born to dams treated with PolyI:C during pregnancy, regardless of the postnatal rearing condition (Fig. 6a). These impressions were supported by the significant main effect of pre-exposure $[F(1,27)=4.56, P<0.05]$ and its interaction with prenatal treatment $[F(1,27)=8.40, P<0.01]$. Subsequent analyses restricted to both prenatal treatment conditions confirmed a significant LI effect in animals born to dams treated with vehicle during pregnancy $[F(1,15)=16.24, P<0.01]$ but not in prenatally PolyI:Ctreated offspring $[F<1.0, \mathrm{~ns}]$. No other main effects or interactions attained statistical significance.

Additional analyses showed that the significant preexposure $\times$ prenatal treatment interaction term stemmed primarily from a prenatal treatment effect in the PE condition. An ANOVA restricted to the PE subjects yielded a significant main effect of prenatal treatment $[F(1,16)=8.29$, $P<0.05$ ], whilst this main effect in the analysis restricted to the NPE subjects was far from statistical significance $[F(1,15)=1.18, P=0.20]$. This suggested that prenatal PolyI:C treatment attenuated the effects of CS pre-exposure on subsequent conditioned taste aversion learning.

An analysis of the total amount of liquid consumed (sucrose solution and water) was also carried out to examine any possible effects of the prenatal and postnatal treatment conditions on drinking behaviour per se. A $2 \times 2 \times 2$ (prenatal treatment $\times$ postnatal rearing $\times$ preexposure) randomized block ANOVA of this measure yielded no significant main effects or interactions, and notably the liquid consumption on the test day did not differ across the four treatment groups or between the two pre-exposure conditions (Fig. 6b).

POL - SAL
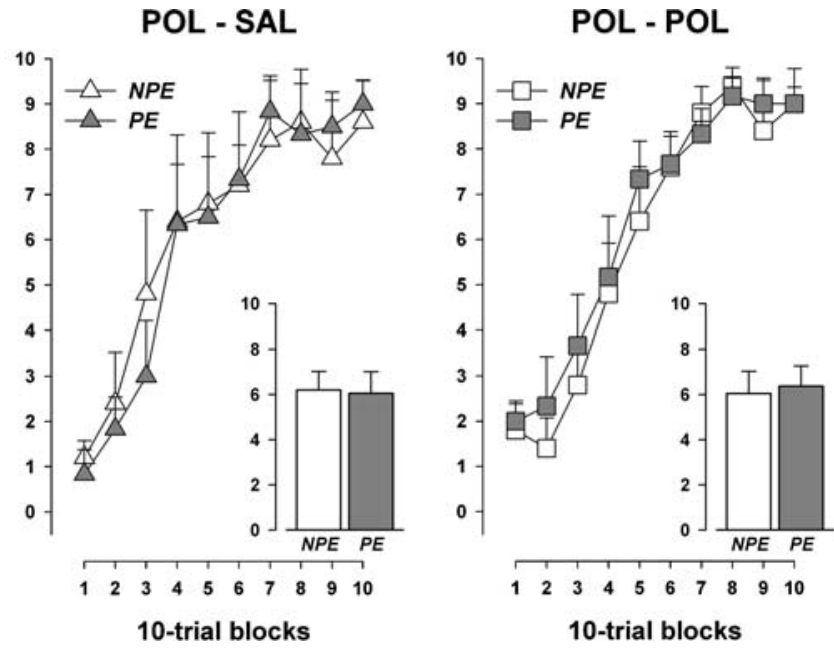

surrogate mothers $(S A L-S A L)$. The prenatal exposure to PolyI:C resulted in the abolition of $\mathrm{LI}$ in adulthood, regardless of the postnatal rearing condition (i.e. in adult $P O L-S A L$ and $P O L-P O L$ animals). In addition, a loss of the LI effect was also observed in prenatally vehicle-treated offspring that were raised by PolyI:C-exposed surrogate mothers $(S A L-P O L)$. All values refer to mean \pm SEM. Symbol $(* *)$ refers to a statistical significance of $P<0.01$ based on separate ANOVAs restricted to each experimental condition
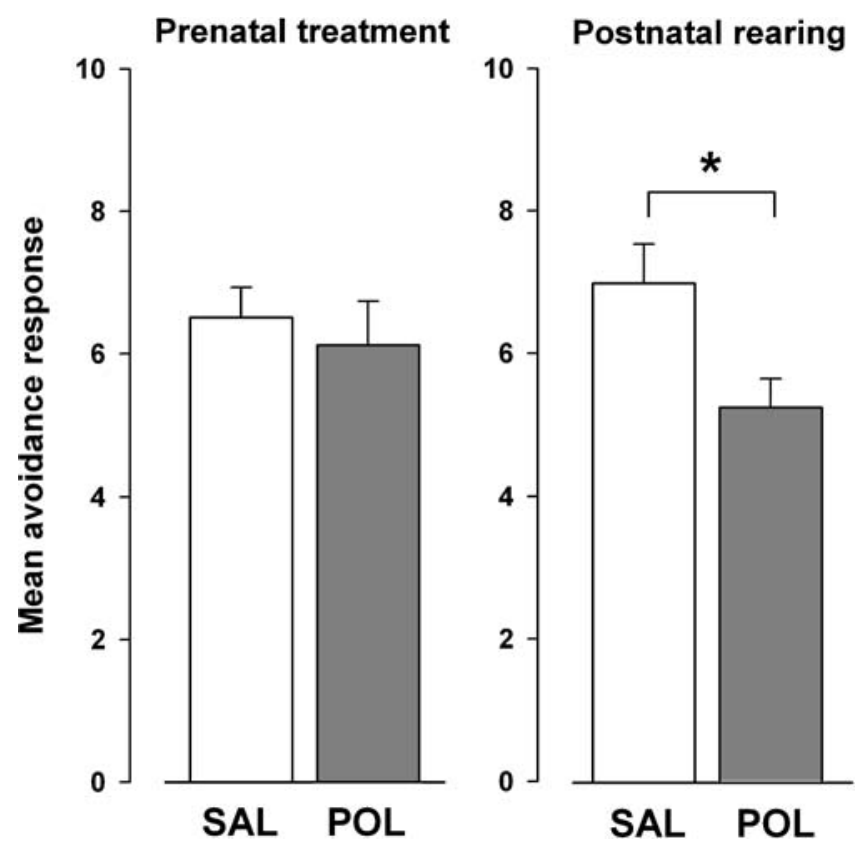

Fig. 5 The effects of the prenatal and postnatal manipulations on the acquisition of conditioned avoidance learning in the NPE condition in adulthood. The graph illustrates the overall mean avoidance response per ten-trial block displayed by NPE subjects across a total of 100 conditioning trials. The adoption of neonates by PolyI:C-challenged surrogate mothers (POL) retarded the acquisition of conditioned avoidance learning in adulthood compared to offspring raised by SAL-treated surrogate mothers. On the other hand, the prenatal treatment history exerted virtually no effect on conditioned avoidance learning per se. All values refer to mean \pm SEM. Symbol $(*)$ refers to a statistical significance of $P<0.05$ associated with the main effect of postnatal rearing taken from the corresponding ANOVA restricted to NPE animals 

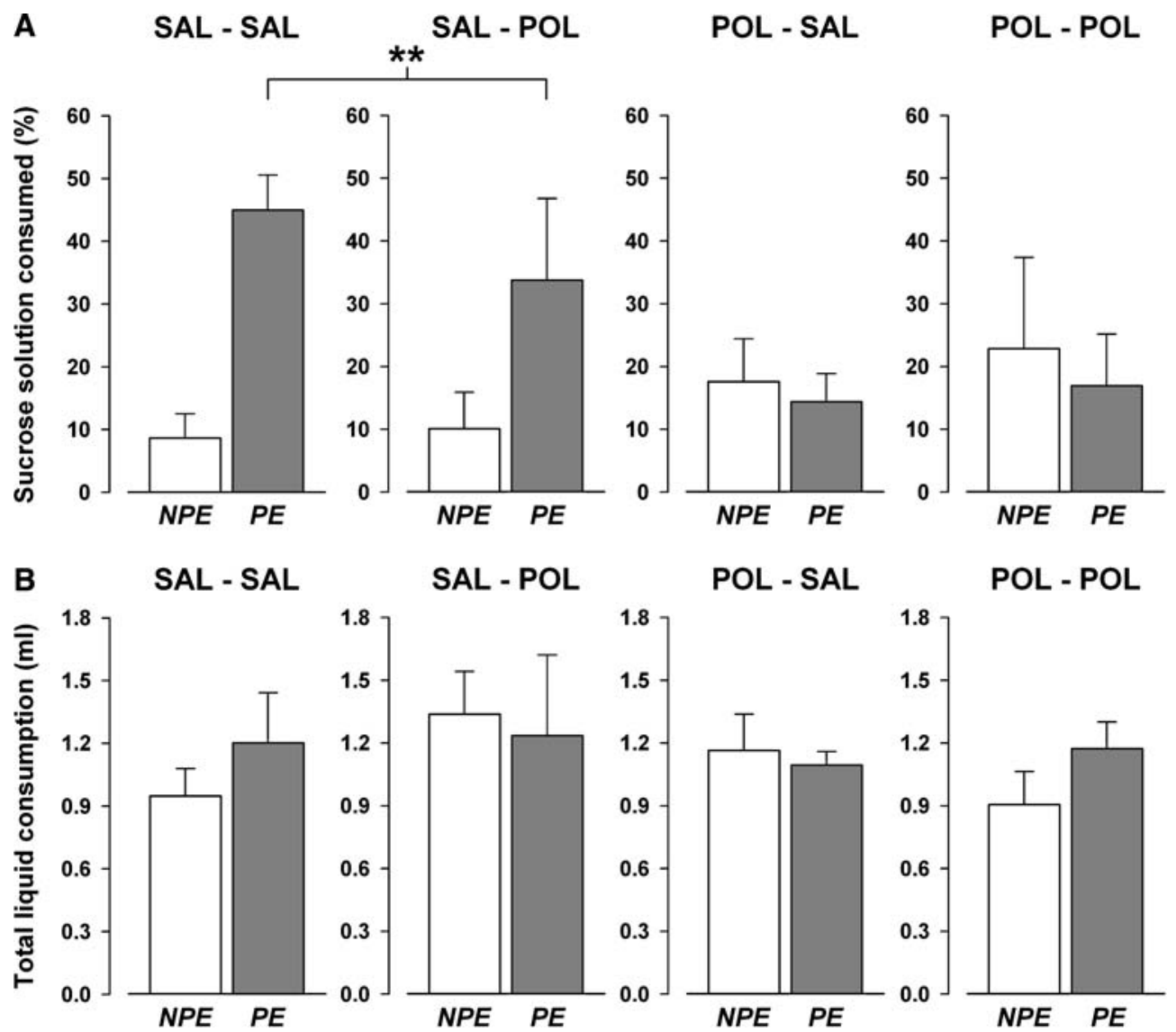

Fig. 6 The effects of the prenatal and postnatal manipulations on LI in a conditioned taste aversion paradigm in adulthood. Conditioned taste aversion was demonstrated using a two-bottle test procedure and was indexed by the preference for the sucrose solution expressed in percentage of total liquid (sucrose solution and water) consumed on the test session. a Pre-exposure to the sucrose solution led to reduced conditioned taste aversion in adult animals subjected to prenatal (saline) treatment regardless of the postnatal rearing condition (i.e. in adult $S A L-S A L$ and $S A L-P O L$ offspring). In contrast, this LI effect was lost in adult offspring exposed to prenatal PolyI:C treatment independent of the neonatal adoption procedure

\section{Discussion}

The present study replicated and extended the findings from our previous reports that the maternal exposure to PolyI:C at gestation day 9 in mice led to the attenuation of LI in a conditioned freezing paradigm in the adult offspring (Meyer et al. 2005, 2006). Here, a post-pubertal loss of LI following prenatal immunological stimulation was demonstrated in both active avoidance learning (Experiment 2) and conditioned taste aversion (Experiment 3 ). This readily suggests that the disruptive effects of prenatal PolyI:C treatment on LI expression in adulthood can be demonstrated independently of the conditioning procedure used. Moreover, our data support the findings from previous studies in rats showing that LI deficiency following prenatal immune activation exhibits a post-pubertal maturational delay (Zuckerman et al. 2003a; Zuckerman and Weiner 2003), i.e. prenatal

(i.e. in adult $P O L-S A L$ and $P O L-P O L$ animals). b The prenatal treatment did not exert any effects on drinking behaviour per se, as the total amount of liquid consumption on the test day did not differ across prenatal and pre-exposure conditions. All values refer to mean \pm SEM. Symbol $(* *)$ refers to a statistically significant difference $(P<0.01)$ between the PE animals exposed to prenatal vehicle treatment $(S A L-S A L$ and $S A L-P O L)$ and the combined NPE animals subjected to prenatal vehicle exposure $(S A L-S A L$ and $S A L-$ $P O L$ ), as indicated by the main effect of pre-exposure taken from the corresponding ANOVA restricted to the prenatal vehicle treatment $[F(1,15)=16.24,(P<0.01)]$

PolyI:C exposure results in the disruption of LI only in adulthood but not at a juvenile stage of development. Indeed, the acquisition and expression of LI during preadolescence was, if anything, enhanced in animals subjected to prenatal PolyI:C exposure compared to prenatally vehicle-treated offspring (see Figs. 1, 2). Thus, a maturational delay between the immunological manipulation in utero and the onset of psychopathology in adulthood exists, and this is consistent with the developmental aetiology and disease process of schizophrenia and related disorders (Jakob and Beckman 1986; Weinberger 1987; Rapoport et al. 2005). However, the present findings of juvenile and adult LI deficiency in prenatal control animals that were raised by PolyI:C-treated surrogate mothers (Figs. 2, 4) highlight the possibility that immunological stress during pregnancy may affect maternal postpartum factors in such a way that the adoption of prenatal control animals by immune-challenged surrogate mothers is sufficient to precipitate 
learning deficits in the offspring. Specifically, these learning disabilities do not seem to be dependent on postpubertal maturational processes, as they are equally present in pre-adolescence and adulthood.

Our attempts here to dissect the relative contributions of prenatal inflammatory events and postnatal maternal factors in the prenatal immune activation model have demonstrated that the gestational treatment histories of the rearing mother does not modulate the post-pubertal emergence of LI deficiency in offspring subjected to prenatal immune challenge. This is because the behavioural abnormalities emerging in animals subjected to prenatal PolyI:C exposure were independent of the postnatal adoption procedure, suggesting furthermore that the prenatal immunological manipulation induces robust maturation-dependent deficits in LI. It thus appears that the adoption of prenatally immune challenged neonates by control surrogate rearing mothers does not have any beneficial effects on the later appearance of selective learning deficits. Rather, the present results provide further support for the hypothesis that inflammation-mediated disruption of foetal brain development may predispose the early-life organism to the emergence of psychopathology in later life (Gilmore and Jarskog 1997; Pearce 2001; Patterson 2002; Brown et al. 2004a, b). In addition, our results provide no experimental evidence for the possibility that additive effects may exist between prenatal immunological stress and the postnatal adoption by immune-challenged surrogate rearing mothers, at least in the precipitation of deficiency in selective learning.

However, we also clearly demonstrated a pre- and post-pubertal loss of the LI effect in prenatally vehicletreated animals that were adopted by a PolyI:C-treated surrogate mother (Figs. 2, 4). At both stages of development, this LI deficiency was largely mediated by reduced learning in the NPE subjects, indicating that the pre- and post-pubertal loss of LI in prenatal control offspring that were raised by PolyI:C-treated surrogate mothers may readily be attributable to a general deterioration in cognitive functions as such rather than to impairments in selective attention. Hence, our findings highlight for the first time that putative changes in postnatal maternal factors as a result of immune challenge during pregnancy are sufficient to lead to the emergence of learning disabilities in the juvenile and adult offspring. Since postpartum maternal behaviour and milk quality are the two crucial factors that are transmitted from the mother to the neonates (Fleming et al. 1999; Leckman and Herman 2002; Walker et al. 2004), the experience of immunological stress during pregnancy may adversely affect the quality (and/or quantity) of these factors and thus subject the organism with an unfavourable rearing environment in early life. Previous studies have already indicated that early life adversity can affect postnatal growth and brain development, and the disruption of which is linked to the eventual appearance of psychopathological behaviour later in life (reviewed in Weiss and Feldon 2001; Cirulli et al. 2003; Pryce and Feldon 2003; Pryce et al. 2005).
The emergence of a post-pubertal reduction in body weight as a function of the adoption by immune-challenged rearing mothers further supports the possibility that PolyI:C-induced immunological stress during pregnancy may have critical impact on postpartum maternal factors.

It needs to be emphasized, however, that such putative alterations in maternal postpartum factors appeared to exert distinct effects in the offspring depending on their prenatal treatment histories. This is supported by the observation that only prenatally vehicle-treated offspring that were raised by PolyI:C-exposed surrogate mothers displayed LI deficits in pre-adolescence. In contrast, prenatal PolyI:C-offspring that were adopted by PolyI:C-exposed surrogate mothers showed normal or even enhanced LI at this stage of development. Since each surrogate mother concomitantly raised pups of both prenatal treatment conditions, it is unlikely that these distinct effects on the development of LI could be accounted for by within-litter differences in maternal behaviour towards the pups, because maternal behaviour is most often directed by and transmitted to the whole litter (Fleming et al. 1999; Walker et al. 2004). Rather, the ultimate impact of putative changes in postnatal maternal factors on postnatal brain development and associated behaviour in the offspring may be influenced by the prenatal treatment history. The data here readily suggest that offspring may be less sensitive to changes in maternal postnatal factors when they had been exposed to prenatal immunological stimulation compared to offspring that had received prenatal vehicle treatment only.

Previous studies in rats have indicated that the sensitivity of juvenile LI (at PND 35) to acute dopaminergic stimulation markedly differs from its capacity to disrupt LI in adulthood (Zuckerman et al. 2003b). In contrast to adult rodents, where the efficacy of low doses of amphetamine to abolish LI is well established (e.g. Weiner et al. 1984, 1988; Russig et al. 2003; Meyer et al. 2004, reviewed in Moser et al. 2000; Weiner 2003), it has been demonstrated by Zuckerman et al. (2003b) that LI in juvenile rats is resistant to the disruptive effects of low doses of amphetamine. The disruption of LI in adult rats by amphetamine is likely to be dopamine-mediated, because the amphetamine-induced attenuation of LI can be reversed by the administration of the dopaminereceptor antagonist, haloperidol (e.g. Warburton et al. 1994; Russig et al. 2003). The failure of amphetamine to disrupt LI in pre-adolescence is in agreement with the findings that the mesolimbic dopaminergic system is not fully developed at a juvenile stage of development (Infurna and Spear 1979; Bolanos et al. 1998; Andersen et al. 2001; Spear 2000). Zuckerman et al. (2003b) went on to show, however, that LI of juvenile rats can be attenuated by serotonergic manipulations, suggesting that the serotonergic modulation of LI is already operative in preadolescence and is, in contrast to the dopamine-related modulatory systems, not dependent on post-pubertal maturational processes. Hence, the loss of LI in juvenile 
offspring that were subjected to prenatal vehicle treatment and raised by PolyI:C-exposed surrogate mothers here is likely attributable to disturbances in the central serotonergic system. It will therefore be of great interest to further elucidate the pharmacological sensitivity of juvenile (and adult) offspring raised by immune-challenged surrogate mothers in order to characterize more specifically the neurochemical basis of the loss of LI in these animals.

It follows that the neural basis of the post-pubertal loss of LI due to prenatal PolyI:C exposure (regardless of the postnatal rearing condition) may differ from that one precipitated by the adoption of prenatal control animals by PolyI:C-exposed rearing mothers. Not only has the former emerged after a post-pubertal maturational delay, whilst the latter was already manifested in pre-adolescence, but the prenatal and postnatal manipulations exerted distinct long-term effects on avoidance learning as such. Whereas the adoption of offspring by PolyI:C-treated mothers impaired adult avoidance learning in the NPE condition (Fig. 5), prenatal PolyI:C administration facilitated avoidance responding in adult CS-PE subjects. Hence, similar to the findings obtained in the conditioned freezing paradigm in pre-adolescence (Figs. 2, 3), impaired conditioning in the NPE condition has contributed to the attenuation of adult LI in the active avoidance paradigm in prenatal control animals that were adopted by PolyI:C-treaded surrogate rearing mothers. In contrast, the efficacy of prenatal PolyI:C exposure to disrupt adult LI in active avoidance learning stemmed solely from its effects on improving conditioned responding in the PE condition. The latter suggestion is in full agreement with the findings that the prenatal PolyI:C-induced abolition of adult LI in the conditioned taste aversion paradigm was also clearly mediated by a facilitation in the learning performance of prenatally PolyI:C-exposed PE animals relative to the NPE subjects (Fig. 6a).

Further support for the possibility that the nature of adult LI deficiency is dissimilar between animals subjected to prenatal immune challenge and prenatal control animals that were raised by PolyI:C-treated surrogate mothers is provided by the observation that the long-term behavioural consequences of prenatal immune activation were similarly detectable in both aversive instrumental (i.e. conditioned active avoidance) and classical Pavlovian (i.e. conditioned taste aversion) conditioning. Conversely, the efficacy of the postnatal PolyI:C-rearing condition to abolish LI in adulthood was only apparent in active avoidance learning, but not in the conditioned taste aversion paradigm. As reviewed elsewhere (Moser et al. 2000; Weiner 2003), the LI effect is demonstrable across a variety of Pavlovian and instrumental conditioning procedures, but recent experimentation in animals has indicated that the efficacy of manipulations affecting its development and/or expression is not always generalizable one conditioning paradigm to the other (see e.g. Reilly et al. 1993; Purves et al. 1995; Gallo and Candido 1995; Buhusi et al. 1998; Schmajuk et al. 2000, 2001; Oswald et al. 2002; Schmajuk
2005; Pothuizen et al. 2006). This may further indicate the possibility that distinct neural substrates are involved in the regulation and modulation of LI depending on the specific conditioning procedure used (Schmajuk et al. 2000; Schmajuk 2005). Here, we found that the adoption of prenatally vehicle-treated neonates by PolyI:C-exposed surrogate rearing mothers produced a paradigm-specific disruption of adult LI, whilst prenatal immune challenge attenuated adult LI independent of the conditioning procedure used. Hence, the use of multiple associative learning procedures has allowed us to detect a potentially important distinction between the mechanism underlying the disruptive effects of the prenatal and postnatal manipulations on adult LI, respectively.

The present study provided the first experimental evidence for the emergence of maturation-independent learning disabilities following neonatal rearing by immune-challenged surrogate mothers. The mechanisms underlying this association are virtually unknown, because the role of postnatal maternal factors have received scant attention in the link between maternal immune activation during pregnancy and the higher risk for psychosis-related abnormalities in the resulting offspring. The induction of maternal stress responses, however, might represent one way as to how maternal postnatal factors could be affected by immunological stimulation during pregnancy. Indeed, stimulation of the peripheral immune system is immediately accompanied by the activation of the stress response axes (Goebel et al. 2002; Haddad et al. 2002; Webster and Sternberg 2004; Silverman et al. 2005), and maternal physiological and/or psychological stress during pregnancy can alter postpartum maternal behaviour (Brayden et al. 1992; Maughan and McCarthy 1997; Meek et al. 2001; Patin et al. 2002). The future investigations of the potential effects of gestational immune challenge on postpartum maternal behaviour and physiology will therefore be highly relevant for the elucidation of mechanisms underlying the link between the adoption of neonates by immune-challenged surrogate mothers and the precipitation of juvenile and adult learning deficits.

Acknowledgements The present study was supported by the Swiss Federal Institute of Technology Zurich, with additional support from the National Centre for Competence in Research: Neural Plasticity and Repair, Swiss National Science Foundation. We are extremely grateful to Peter Schmid for his technical assistance. We also remain indebted to Jeanne Michel and Pascal Guela for their care of the animals, and to Dr. Frank Bootz for his veterinary expertise.

\section{References}

Andersen SL, LeBlanc CJ, Lyss PJ (2001) Maturational increases in c-fos expression in the ascending dopamine systems. Synapse 41:345-350

Ashdown H, Dumont Y, Ng M, Poole S, Boksa P, Luheshi GN (2006) The role of cytokines in mediating effects of prenatal infection on the fetus: implications for schizophrenia. Mol Psychiatry 11:47-55 
Bolanos CA, Glatt SJ, Jackson D (1998) Subsensitivity to dopaminergic drugs in periadolescent rats: a behavioral and neurochemical analysis. Brain Res Dev Brain Res 111:25-33

Borrell J, Vela JM, Arévalo-Martin A, Molina-Holgado E, Guaza C (2002) Prenatal immune challenge disrupts sensorimotor gating in adult rats: implications for the etiopathogenesis of schizophrenia. Neuropsychopharmacology 26:204-221

Bracha HS, Torrey EF, Bigelow LB, Lohr JB, Linington BB (1991) Subtle signs of prenatal maldevelopment of the hand ectoderm in schizophrenia: a preliminary monozygotic twin study. Biol Psychiatry 30:719-725

Bracha HS, Torrey EF, Gottesman II, Bigelow LB, Cunniff C (1992) Second-trimester markers of fetal size in schizophrenia: a study of monozygotic twins. Am J Psychiatry 149:1355-1361

Brake WG, Zhang TY, Diorio J, Meaney MJ, Gratton A (2004) Influence of early postnatal rearing conditions on mesocorticolimbic dopamine and behavioural responses to psychostimulants and stressors in adult rats. Eur J Neurosci 19:1863-1874

Brayden RM, Altemeier WA, Tucker DD, Dietrich MS, Vietze P (1992) Antecedents of child neglect in the first two years of life. J Pediatr 120:426-429

Brown AS, Schaefer CA, Wyatt RJ, Goetz R, Begg MD, Gorman JM, Susser ES (2000) Maternal exposure to respiratory infections and adult schizophrenia spectrum disorders: a prospective birth cohort study. Schizophr Bull 26:287-295

Brown AS, Begg MD, Gravenstein S, Schaefer CA, Wyatt RJ, Bresnahan M, Babulas VP, Susser ES (2004a) Serologic evidence of prenatal influenza in the etiology of schizophrenia. Arch Gen Psychiatry 61:774-780

Brown AS, Hooton J, Schaefer CA, Zhang H, Petkova E, Babulas V, Perrin M, Gorman JM, Susser ES (2004b) Elevated maternal interleukin-8 levels and risk of schizophrenia in adult offspring. Am J Psychiatry 161:889-895

Buhusi CV, Gray JA, Schmajuk NA (1998) Perplexing effects of hippocampal lesions on latent inhibition: a neural network solution. Behav Neurosci 112:316-351

Buka SL, Tsuang MT, Torrey EF, Klebanoff MA, Wagner RL, Yolken RH (2001) Maternal cytokine levels during pregnancy and adult psychosis. Brain Behav Immun 15:411-420

Cardno AG, Marshall EJ, Coid B, Macdonald AM, Ribchester TR, Davies NJ, Venturi P, Jones LA, Lewis SW, Sham PC, Gottesman II, Farmer AE, McGuffin P, Reveley AM, Murray RM (1999) Heritability estimates for psychotic disorders: the Maudsley twin psychosis series. Arch Gen Psychiatry 56:162-168

Cirulli F, Berry A, Alleva E (2003) Early disruption of the motherinfant relationship: effects on brain plasticity and implications for psychopathology. Neurosci Biobehav Rev 27:73-82

Ellenbroek BA, Cools AR (2002) Early maternal deprivation and prepulse inhibition: the role of the postdeprivation environment. Pharmacol Biochem Behav 73:177-184

Fatemi SH, Emamian ES, Kist D, Sidwell RW, Nakajima K, Akhter P, Shier A, Sheikh S, Bailey K (1999) Defective corticogenesis and reduction in Reelin immunoreactivity in cortex and hippocampus of prenatally infected neonatal mice. Mol Psychiatry 4:145-154

Fatemi SH, Earle J, Kanodia R, Kist D, Emamian ES, Patterson PH, Shi L, Sidwell R (2002) Prenatal viral infection leads to pyramidal cell atrophy and macrocephaly in adulthood: implications for genesis of autism and schizophrenia. Cell Mol Neurobiol 22:25-33

Fatemi SH, Pearce DA, Brooks AI, Sidwell RW (2005) Prenatal viral infection in mouse causes differential expression of genes in brains of mouse progeny: a potential animal model for schizophrenia and autism. Synapse 57:91-99

Feldon J, Weiner I (1992) From an animal model of an attentional deficit towards new insights into the pathophysiology of schizophrenia. J Psychiatr Res 26:345-366

Fleming AS, O'Day DH, Kraemer GW (1999) Neurobiology of mother-infant interactions: experience and central nervous system plasticity across development and generations. Neurosci Biobehav Rev 23:673-685

Fortier ME, Joober R, Luheshi GN, Boksa P (2004) Maternal exposure to bacterial endotoxin during pregnancy enhances amphet- amine-induced locomotion and startle responses in adult rat offspring. J Psychiatr Res 38:335-345

Franzek E, Beckmann H (1996) Gene-environment interaction in schizophrenia: season-of-birth effect reveals etiologically different subgroups. Psychopathology 29:14-26

Frith CD (1979) Consciousness, information processing and schizophrenia. Br J Psychiatry 134: 225-235

Gallo M, Candido A (1995) Dorsal hippocampal lesions impair blocking but not latent inhibition of taste aversion learning in rats. Behav Neurosci 109:413-425

Gilmore JH, Jarskog LF (1997) Exposure to infection and brain development: cytokines in the pathogenesis of schizophrenia. Schizophr Res 24:365-367

Gilmore JH, Perkins DO, Kliewer MA, Hage ML, Silva SG, Chescheir NC, Hertzberg BS, Sears CA (1996) Fetal brain development of twins assessed in utero by ultrasound: implications for schizophrenia. Schizophr Res 19:141-149

Gilmore JH, Jarskog LF, Vadlamudi S, Lauder JM (2004) Prenatal infection and risk for schizophrenia: IL-1beta, IL-6, and TNFalpha inhibit cortical neuron dendrite development. Neuropsychopharmacology 29:1221-1229

Gilmore JH, Jarskog LF, Vadlamudi S (2005) Maternal poly I:C exposure during pregnancy regulates TNFalpha, BDNF, and NGF expression in neonatal brain and the maternal-fetal unit of the rat. J Neuroimmunol 159:106-112

Goebel MU, Baase J, Pithan V, Exton M, Saller B, Schedlowski M, Limmroth V (2002) Acute interferon beta-1b administration alters hypothalamic-pituitary-adrenal axis activity, plasma cytokines and leukocyte distribution in healthy subjects. Psychoneuroendocrinology 27:881-892

Golan HM, Lev V, Hallak M, Sorokin Y, Huleihel M (2005) Specific neurodevelopmental damage in mice offspring following maternal inflammation during pregnancy. Neuropharmacology 48:903-917

Gray JA (1998) Integrating schizophrenia. Schizophr Bull 24:249 266

Gray JA, Feldon J, Rawlins JNP, Hemsley DR, Smith AD (1991) The neuropsychology of schizophrenia. Behav Brain Sci 14:1-84

Haddad JJ, Saade NE, Safieh-Garabedian B (2002) Cytokines and neuro-immune-endocrine interactions: a role for the hypothalamic-pituitary-adrenal revolving axis. J Neuroimmunol 133:119

Harrison PJ, Weinberger DR (2005) Schizophrenia genes, gene expression, and neuropathology: on the matter of their convergence. Mol Psychiatry 10:40-68

Hemsley DR (1976) Attention and information processing in schizophrenia. Br J Soc Clin Psychol 15:199-209

Hultman CM, Sparen P, Takei N, Murray RM, Cnattingius S (1999) Prenatal and perinatal risk factors for schizophrenia, affective psychosis and reactive psychosis. Br J Med 310:421-425

Infurna RN, Spear LP (1979) Developmental changes in amphetamine-induced taste aversions. Pharmacol Biochem Behav $11: 31-35$

Jakob H, Beckman H (1986) Prenatal development disturbances in the limbic allocortex in schizophrenia. J Neural Transm 65:303326

Kendler KS, Gardner CO, Prescott CA (2002) Toward a comprehensive developmental model for major depression in women. Am J Psychiatry 159:1133-1145

Kendler KS, Gardner CO, Prescott CA (2006) Toward a comprehensive developmental model for major depression in men. Am J Psychiatry 163:115-124

Leckman JF, Herman AE (2002) Maternal behavior and developmental psychopathology. Biol Psychiatry 51:27-43

Lehmann J, Feldon J (2000) Long-term biobehavioral effects of maternal separation in the rat: consistent or confusing? Rev Neurosci 11:383-408

Mäki P, Veijola J, Jones PB, Murray GK, Koponen H, Tienari P, Miettunen J, Tanskanen P, Wahlberg KE, Koskinen J, Lauronen E, Isohanni M (2005) Predictors of schizophrenia - a review. Br Med Bull 73:1-15

Maughan B, McCarthy G (1997) Childhood adversities and psychosocial disorders. Br Med Bull 53:156-169 
Mednick SA, Machon RA, Huttunen MO, Bonett D (1988) Adult schizophrenia following prenatal exposure to an influenza epidemic. Arch Gen Psychiatry 45:189-192

Meek LR, Dittel PL, Sheehan MC, Chan JY, Kjolhaug SR (2001) Effects of stress during pregnancy on maternal behavior in mice. Physiol Behav 72:473-479

Meyer U, Chang de LT, Feldon J, Yee BK (2004) Expression of the CS- and US-pre-exposure effects in the conditioned taste aversion paradigm and their abolition following systemic amphetamine treatment in C57BL6/J mice. Neuropsychopharmacology 29:2140-2148

Meyer U, Feldon J, Schedlowski M, Yee BK (2005) Towards an immuno-precipitated neurodevelopmental animal model of schizophrenia. Neurosci Biobehav Rev 29:913-947

Meyer U, Feldon J, Schedlowski M, Yee BK (2006) Immunological stress at the maternal-foetal interface: a link between neurodevelopment and adult psychopathology. Brain Behav Immun (in press)

Moser PC, Hitchcock JM, Lister S, Moran PM (2000) The pharmacology of latent inhibition as an animal model of schizophrenia. Brain Res Rev 33:275-307

Murray RM, Jones P, O'Callaghan E (1991) Fetal brain development and later schizophrenia. Ciba Found Symp 156:155-163

Nuechterlein KH, Dawson ME (1984) Information processing and attentional functioning in the developmental course of schizophrenic disorders. Schizophr Bull 10:160-203

O'Callaghan E, Sham PC, Takei N, Murray G, Glover G, Hare EH, Murray RM (1994) The relationship of schizophrenic births to 16 infectious diseases. Br J Psychiatry 165:353-356

Oswald CJ, Yee BK, Rawlins JN, Bannerman DB, Good M, Honey RC (2002) The influence of selective lesions to components of the hippocampal system on the orienting response, habituation and latent inhibition. Eur J Neurosci 15:1983-1990

Ozawa K, Hashimoto K, Kishimoto T, Shimizu E, Ishikura H, Iyo M (2006) Immune activation during pregnancy in mice leads to dopaminergic hyperfunction and cognitive impairment in the offspring: a neurodevelopmental animal model of schizophrenia. Biol Psychiatry 59:546-554

Parker G, Hadzi-Pavlovic D, Greenwald S, Weissman M (1995) Low parental care as a risk factor to lifetime depression in a community sample. J Affect Disord 33:173-180

Patin V, Lordi B, Vincent A, Thoumas JL, Vaudry H, Caston J (2002) Effects of prenatal stress on maternal behavior in the rat. Brain Res Dev Brain Res 139:1-8

Patterson PH (2002) Maternal infection: window on neuroimmune interactions in fetal brain development and mental illness. Curr Opin Neurobiol 12:115-118

Pearce BD (2001) Schizophrenia and viral infection during neurodevelopment: a focus on mechanisms. Mol Psychiatry 6:634-646

Perry W, Braff DL (1994) Information-processing deficits and thought disorder in schizophrenia. Am J Psychiatry 151:363-367

Petronis A (2004) The origin of schizophrenia: genetic thesis, epigenetic antithesis, and resolving synthesis. Biol Psychiatry 55:965970

Pothuizen HH, Jongen-Relo AL, Feldon J, Yee BK (2006) Latent inhibition of conditioned taste aversion is not disrupted, but can be enhanced, by selective nucleus accumbens shell lesions in rats. Neuroscience 137:1119-1130

Pryce CR, Feldon J (2003) Long-term neurobehavioural impact of the postnatal environment in rats: manipulations, effects and mediating mechanisms. Neurosci Biobehav Rev 27:57-71

Pryce CR, Ruedi-Bettschen D, Dettling AC, Weston A, Russig H, Ferger B, Feldon J (2005) Long-term effects of early-life environmental manipulations in rodents and primates: potential animal models in depression research. Neurosci Biobehav Rev 29:649 674

Purves D, Bonardi C, Hall G (1995) Enhancement of latent inhibition in rats with electrolytic lesions of the hippocampus. Behav Neurosci 109:366-370

Rapoport JL, Addington AM, Frangou S, Psych MR (2005) The neurodevelopmental model of schizophrenia: update 2005. Mol Psychiatry 10:434-449
Reilly S, Harley C, Revusky S (1993) Ibotenate lesions of the hippocampus enhance latent inhibition in conditioned taste aversion and increase resistance to extinction in conditioned taste preference. Behav Neurosci 107:996-1004

Russig H, Kovacevic A, Murphy CA, Feldon J (2003) Haloperidol and clozapine antagonise amphetamine-induced disruption of latent inhibition of conditioned taste aversion. Psychopharmacology 170:263-270

Schmajuk N (2005) Brain-behaviour relationships in latent inhibition: a computational model. Neurosci Biobehav Rev 29:10011020

Schmajuk NA, Christiansen B, Cox L (2000) Haloperidol reinstates latent inhibition impaired by hippocampal lesions: data and theory. Behav Neurosci 114:659-670

Schmajuk NA, Cox L, Gray JA (2001) Nucleus accumbens, entorhinal cortex and latent inhibition: a neural network model. Behav Brain Res 118:123-141

Shi L, Fatemi SH, Sidwell RW, Patterson PH (2003) Maternal influenza infection causes marked behavioral and pharmacological changes in the offspring. J Neurosci 23:297-302

Silverman MN, Pearce BD, Biron CA, Miller AH (2005) Immune modulation of the hypothalamic-pituitary-adrenal (HPA) axis during viral infection. Viral Immunol 18:41-78

Spear LP (2000) The adolescent brain and age-related behavioral manifestations. Neurosci Biobehav Rev 24:417-463

Tienari P, Wynne LC, Sorri A, Lahti I, Laksy K, Moring J, Naarala M, Nieminen P, Wahlberg KE (2004) Genotype-environment interaction in schizophrenia-spectrum disorder. Longterm follow-up study of Finnish adoptees. Br J Psychiatry $184: 216-222$

Tsuang M (2000) Schizophrenia: genes and environment. Biol Psychiatry 47:210-220

Urakubo A, Jarskog LF, Lieberman JA, Gilmore JH (2001) Prenatal exposure to maternal infection alters cytokine expression in the placenta, amniotic fluid, and fetal brain. Schizophr Res 47:27-36

Wahlberg KE, Wynne LC, Oja H, Keskitalo P, Pykalainen L, Lahti I, Moring J, Naarala M, Sorri A, Seitamaa M, Laksy K, Kolassa J, Tienari P (1997) Gene-environment interaction in vulnerability to schizophrenia: findings from the Finnish adoptive family study of schizophrenia. Am J Psychiatry 154:355-362

Walker CD, Deschamps S, Proulx K, Tu M, Salzman C, Woodside B, Lupien S, Gallo-Payet N, Richard D (2004) Mother to infant or infant to mother? Reciprocal regulation of responsiveness to stress in rodents and the implications for humans. J Psychiatry Neurosci 29:364-382

Warburton EC, Joseph MH, Feldon J, Weiner I, Gray JA (1994) Antagonism of amphetamine-induced disruption of latent inhibition in rats by haloperidol and ondansetron: implications for a possible antipsychotic action of ondansetron. Psychopharmacology 114:657-664

Webster JI, Sternberg EM (2004) Role of the hypothalamic-pituitary-adrenal axis, glucocorticoids and glucocorticoid receptors in toxic sequelae of exposure to bacterial and viral products. $\mathbf{J}$ Endocrinol 181:207-221

Weinberger DR (1987) Implications of normal brain development for the pathogenesis of schizophrenia. Arch Gen Psychiatry 44:660-669

Weiner I (2003) The "two-headed" latent inhibition model of schizophrenia: modeling positive and negative symptoms and their treatment. Psychopharmacology 169:257-297

Weiner I, Lubow RE, Feldon J (1984) Abolition of the expression but not the acquisition of latent inhibition by chronic amphetamine in rats. Psychopharmacology 83:194-199

Weiner I, Lubow RE, Feldon J (1988) Disruption of latent inhibition by acute administration of low doses of amphetamine. Pharmacol Biochem Behav 30:871-888

Weiss IC, Feldon J (2001) Environmental animal models for sensorimotor gating deficiencies in schizophrenia: a review. Psychopharmacology 156:305-326

Weiss IC, Domeney AM, Heidbreder CA, Moreau JL, Feldon J (2001) Early social isolation, but not maternal separation, affects 
behavioral sensitization to amphetamine in male and female adult rats. Pharmacol Biochem Behav 70:397-409

Zorrilla EP (1997) Multiparous species present problems (and possibilities) to developmentalists. Dev Psychobiol 30:141-150

Zuckerman L, Weiner I (2003) Post-pubertal emergence of disrupted latent inhibition following prenatal immune activation. Psychopharmacology 169:308-313

Zuckerman L, Weiner I (2005) Maternal immune activation leads to behavioral and pharmacological changes in the adult offspring. $\mathbf{J}$ Psychiatr Res 39:311-323
Zuckerman L, Rehavi M, Nachman R, Weiner I (2003a) Immune activation during pregnancy in rats leads to a postpubertal emergence of disrupted latent inhibition, dopaminergic hyperfunction, and altered limbic morphology in the offspring: a novel neurodevelopmental model of schizophrenia. Neuropsychopharmacology 28:1778-1789

Zuckerman L, Rimmerman N, Weiner I (2003b) Latent inhibition in 35-day-old rats is not an "adult" latent inhibition: implications for neurodevelopmental models of schizophrenia. Psychopharmacology 169:298-307 